Article

\title{
Pediatric Integrative Medicine in Residency Program: Relationship between Lifestyle Behaviors and Burnout and Wellbeing Measures in First-Year Residents
}

\author{
Hilary McClafferty ${ }^{1, *}$, Audrey J. Brooks ${ }^{1, *}$, Mei-Kuang Chen ${ }^{1}$, Michelle Brenner ${ }^{2}$, \\ Melanie Brown ${ }^{3}$, Anna Esparham ${ }^{4}$ (D), Dana Gerstbacher ${ }^{5}$, Brenda Golianu ${ }^{6}$ (D), John Mark ${ }^{5}$, \\ Joy Weydert ${ }^{4}$, Ann Ming Yeh ${ }^{5}$ and Victoria Maizes ${ }^{1}$ \\ 1 Department of Medicine, Arizona Center for Integrative Medicine, University of Arizona, \\ Tucson, AZ 85724, USA; kuang@email.arizona.edu (M.-K.C.); vmaizes@email.arizona.edu (V.M.) \\ 2 Department of Pediatrics, Eastern Virginia Medical School/Children's Hospital of the King's Daughters, \\ Norfolk, VA 23507, USA; michelle.brenner@chkd.org \\ 3 Department of Pediatrics, University of Chicago Comer Children's Hospital, Chicago, IL 60637, USA; \\ Melanie.Brown@childrensmn.org \\ 4 Department of Pediatrics, University of Kansas School of Medicine, Kansas City, KS 66160, USA; \\ aeesparham@cmh.edu (A.E.); jweydert@kumc.edu (J.W.) \\ 5 Department of Pediatrics, Stanford University School of Medicine, Palo Alto, CA 94304, USA; \\ gerst1@stanford.edu (D.G.); jmark@stanford.edu (J.M.); annming@stanford.edu (A.M.Y.) \\ 6 Department of Anesthesiology and Pain Management, Stanford University School of Medicine, \\ Palo Alto, CA 94304, USA; bgolianu@stanford.edu \\ * Correspondence: hmcclafferty@email.arizona.edu (H.M.); brooksaj@email.arizona.edu (A.J.B.)
}

Received: 9 February 2018; Accepted: 17 April 2018; Published: 23 April 2018

\begin{abstract}
It is widely recognized that burnout is prevalent in medical culture and begins early in training. Studies show pediatricians and pediatric trainees experience burnout rates comparable to other specialties. Newly developed Accreditation Council for Graduate Medical Education (ACGME) core competencies in professionalism and personal development recognize the unacceptably high resident burnout rates and present an important opportunity for programs to improve residents experience throughout training. These competencies encourage healthy lifestyle practices and cultivation of self-awareness, self-regulation, empathy, mindfulness, and compassion-a paradigm shift from traditional medical training underpinned by a culture of unrealistic endurance and self-sacrifice. To date, few successful and sustainable programs in resident burnout prevention and wellness promotion have been described. The University of Arizona Center for Integrative Medicine Pediatric Integrative Medicine in Residency (PIMR) curriculum, developed in 2011, was designed in part to help pediatric programs meet new resident wellbeing requirements. The purpose of this paper is to detail levels of lifestyle behaviors, burnout, and wellbeing for the PIMR program's first-year residents $(N=203)$, and to examine the impact of lifestyle behaviors on burnout and wellbeing. The potential of the PIMR to provide interventions addressing gaps in lifestyle behaviors with recognized association to burnout is discussed.
\end{abstract}

Keywords: burnout; pediatrics; residents; preventive lifestyle behaviors; resilience

\section{Introduction}

Medical school and residency training are known for their scientific rigor and daunting hours of service [1,2]. Compounding burnout experienced in medical school, the life of a resident is dominated 
by exposure to significant human suffering, high levels of responsibility, lack of day-to-day control, steep learning curves, limited regeneration time, and chronic sleep deprivation. These realities, in conjunction with patient and family demands, subordinate ranking in the medical hierarchy, and other stressors predispose residents to high burnout prevalence [1,2].

Studies show that pediatricians and pediatric trainees experience burnout at rates comparable to other specialties, with higher prevalence in some high acuity pediatric subspecialties such as neonatology, intensive care, and hematology-oncology [3-6]. Across medical specialties and training levels, burnout has been associated with an increase in medical errors, lower adherence to best practices, substance abuse, self-medication, and poorer patient outcomes (for example, longer hospital stay), in addition to increased rates of clinician's depression, suicidal ideation, and completed suicide [7]. It has been widely reported that effective approaches must include changes at organizational, institutional, and individual levels to address the outdated culture of unrealistic endurance still pervasive in medicine [8].

Newly developed Accreditation Council for Graduate Medical Education (ACGME) core competencies in professionalism and personal development recognize the unacceptably high burnout rates in residents and present an important opportunity for programs to improve the experience of residents at all stages of training [9].

In addition to encouraging healthy lifestyle practices, the core competencies encourage cultivation of self-awareness, self-regulation skills, empathy, mindfulness, and compassion. They also highlight the need for innovation in clinical training and generate questions about how to best teach and measure success in these new areas. This endeavor provides important opportunities to introduce proactive approaches to burnout through a multidimensional model and development of educational curricula that emphasize and measure wellbeing at all phases of medical training.

To date, along with development of the new core competencies, purposeful steps taken by the ACGME include national symposia led by expert national faculty to identify actionable issues, new emphasis on education on physician wellbeing, and recommendations for annual measurement of resident burnout through its Clinical Learning Environmental Review (CLER) program which evaluates the quality of the program learning environment [10].

Despite these significant initiatives, few successful, sustainable programs in resident burnout prevention and wellness promotion have been described. Pediatricians are uniquely positioned to develop national initiatives for solution-based approaches to burnout, in part due to the timely initiation of the 2010 Pediatric Milestone Project, a collaboration between the ACGME and the American Board of Pediatrics (ABP) dedicated to development of revised core competencies. The University of Arizona Center for Integrative Medicine Pediatric Integrative Medicine in Residency (PIMR) curriculum was developed in 2011 and refined in 2012 to include a robust Self-Care unit, partly in response to the new priorities in the revised national pediatric training competencies targeting resident wellbeing outlined by the ACGME.

The 100-h curriculum is an interactive hybrid online-onsite program and has been described in detail in an earlier publication [11]. The program has been piloted since 2012 at the University of Arizona, Stanford University, the University of Kansas, the University of Chicago, and Eastern Virginia Medical School/Children's Hospital of the King's Daughters. The topics covered include: Self-; nutrition and physical activity; mind-body therapies; dietary supplements; whole systems of medicine; and clinical applications.

The curriculum was developed with the two-fold purpose of embedding foundational education in pediatric integrative medicine into residency training and introducing a 'train the trainer' model in teaching healthy lifestyle habits. In anticipation of high levels of burnout in incoming residents, the Self-Care unit was designed to provide an evidence-based 'blueprint' for learning about factors associated with lower burnout prevalence in medical trainees including: physical activity, sleep, stress management, mindfulness, and nutrition, thereby increasing resident knowledge about self-care and also providing a useful educational tool for residency programs to address new ACGME resident 
wellness competency requirements. An integrated evaluation arm measures resident burnout and lifestyle behaviors, and gathers feedback on perceived quality and relevance of the curriculum at four points (beginning, end Post Graduate Year (PGY) 1, end PGY2, end PGY3) of residency training.

We readily acknowledge that change is urgently needed on multiple levels to address the serious issues of preventing burnout and promoting wellbeing in medical trainees, ideally starting in pre-medical and medical students. We believe our study findings detailing the incoming resident levels of burnout, wellbeing, and lifestyle behaviors and examining the relationship between resident lifestyle habits and burnout and wellbeing measures reinforce this point and begin to explore areas of potential progress. The overarching purpose of this paper is to document the concerning state of burnout in early pediatric trainees and to examine the potential of the PIMR curriculum to provide interventions that address gaps in lifestyle behaviors with recognized association to burnout, and how they might be introduced into residency training.

\section{Methods}

Approval for the study was granted by the University of Arizona Institutional Review Board (Approval \#12049200). First-year pediatric residents from five residencies participating in the PIMR program completed standardized wellbeing measures at the start of residency. The PIMR sites include academic and community-based programs led by pediatric faculty with fellowship training in integrative medicine, a field that blends conventional and evidence-based complementary medicine and prioritizes preventive health. Information about existing onsite physician wellness activities was collected and is presented. Data is being collected as part of a longitudinal study on resident wellbeing, burnout and lifestyle behaviors and the longitudinal impact of the PIMR curriculum.

\subsection{Measures}

Residents completed eight widely used, established scales assessing dimensions of well-being: perceived stress, depression symptoms, burnout (emotional exhaustion, depersonalization), life satisfaction, affect, mindfulness, emotional intelligence, and physician empathy (Table 1). A measure of lifestyle behaviors, the Arizona Lifestyle Inventory (ALI) [12], was also administered. The ALI was developed to assess changes in lifestyle behaviors in residents. The domains and items were identified from literature on evidence-based preventive services as well as other areas emphasized by integrative medicine practitioners. The items were reviewed by an expert panel of integrative medicine physicians and were revised based on their comments. The ALI primarily assesses the frequency of behaviors in the past seven days in the areas of diet/nutrition, exercise, mind-body/spiritual practices, social support activities, sleep, and work stress (see Table 2 for items by domain); areas known to mediate the relationships between stress reactivity and physical and mental health. The ALI also includes demographic variables, including hours worked, alcohol use, and health status questions, having a chronic medical condition, taking medication for a chronic medical condition, body mass index (BMI), taking prescription medication for stress or anxiety, days with pain in the past week, and days engaged in hobbies in the past week.

Site leaders completed a survey of onsite physician wellness activities in 2014 and 2016. Physician wellness activities included retreats, nutrition (healthy food options), empathy skills training, conflict resolution/communication skills training, stress management, physical activity options (e.g., exercise rooms), self-regulation skills training (e.g., mind-body skills training), and burnout prevention. 
Table 1. Wellbeing measures.

\begin{tabular}{|c|c|c|}
\hline Dimension & Measure & Description \\
\hline Perceived stress & Perceived Stress Scale (PSS) [13] & 10 items; scores $0-40$ \\
\hline Depression symptoms & $\begin{array}{l}\text { Center for Epidemiologic Studies_-Depression } \\
\text { Scale (CES-D) [14] }\end{array}$ & $\begin{array}{c}20 \text { items; scores range from 0-60; score of } 16 \text { or higher } \\
\text { indicates clinical syndrome }\end{array}$ \\
\hline Burnout & Maslach Burnout Inventory (MBI) $[15,16]$ & $\begin{array}{l}22 \text { items; } 3 \text { subscales emotional exhaustion (EE), } \\
\text { depersonalization (DEP), personal accomplishment (PA) }\end{array}$ \\
\hline Life satisfaction & Satisfaction with Life Scale (SWLS) $[17,18]$ & $\begin{array}{l}5 \text { items; higher total scores indicate greater } \\
\text { life satisfaction }\end{array}$ \\
\hline Affect & Positive and Negative Affect Scale (PANAS) [19] & $\begin{array}{l}20 \text { items; } 2 \text { subscales positive affect (POS), negative affect } \\
\text { (NEG); higher score more positive, more negative affect }\end{array}$ \\
\hline Mindfulness & Freiberg Mindfulness Inventory (FMI) [20] & 14 items, higher score more mindful \\
\hline Emotional Intelligence & Interpersonal Reactivity Index (IRI) [21] & $\begin{array}{c}21 \text { items; } 3 \text { subscales perspective taking (PT), empathic } \\
\text { concern (EC), personal distress (PD); higher scores } \\
\text { greater perspective taking, empathic concern, } \\
\text { personal distress }\end{array}$ \\
\hline
\end{tabular}

\subsection{Data Collection and Statistical Analysis}

Data were collected directly from the residents online using an individualized link to an internet-based survey website (Survey Monkey, San Mateo, CA, USA) in the first trimester of the first year of residency. Prior to accessing the assessments, residents voluntarily completed an online informed consent form. Statistical analyses were conducted using SPSS v. 24.0 (IBM Corp. Released 2016. IBM SPSS Statistics for Windows, Version 24.0. Armonk, NY, USA).

Descriptive statistics are presented for the wellbeing measures and lifestyle behaviors. A burnout risk group variable was created utilizing medicine norms [15] as follows: high burnout consists of individuals scoring in the high range on both emotional exhaustion and depersonalization; low burnout group includes individuals scoring in the low range on both scales; remaining individuals were categorized as moderate burnout. One-way analysis of variance (ANOVA) with post hoc Tukey tests were conducted to compare wellbeing measures and lifestyle behaviors among burnout groups.

A series of multiple regression analyses were performed to examine the relationship between the lifestyle behavior domains and each of the wellbeing measures. For the lifestyle behaviors, due to variation in response format for some items, scale total scores were calculated utilizing two procedures. For scales where all items were rated on a 0-7 scale (number of days of carrying out the specific lifestyle behavior in the past seven days) the scale scores were formed using mean scores of the items in the same domain. For items where there was variation in response format, such as exercise, social support activities, and alcohol use, items were standardized first and then the means of the $z$-scores were used as the scale scores. Items were reverse-scored where indicated. With the exception of the work stress scale, higher scores indicate engaging in more of the behaviors in that domain. Higher scores on the work stress scale indicate a greater level of work stress. The correlation between the wellbeing measures and gender and marital status were examined. If the correlation was statistically significant, gender and/or marital status was included in the model. The initial regression models included all lifestyle variables and demographic variables, as indicated. A final regression analysis was performed dropping non-significant predictors $(p>0.05)$. 


\section{Results}

\subsection{Sample}

The sample consisted of 203 first-year residents from four incoming classes $(2012, n=15 ; 2013$, $n=88 ; 2014, n=59 ; 2015, n=41)$ at five pediatric residency programs participating in the PIMR program: (1) University of Arizona ( $n=41)$; (2) University of Chicago $(n=56)$; (3) Eastern Virginia Medical School/Children's Hospital of the King's Daughters $(n=55)$; (4) University of Kansas Medical Center $(n=26)$; and (5) Stanford University $(n=25)$. The survey response rate across the cohorts was $63 \%$ and ranged between $45-88 \%$ across the residency programs. The sample was predominantly female $(76 \%)$, white $(71 \%)$ or Asian (13\%), and non-Hispanic (94\%) with an average age of 28 years old (range 24-39 years old). Half of the sample was married or cohabitating (50\%) and $12 \%$ had children. The majority of residents were US Doctors of Medicine (76\%), followed by foreign medical graduates (13\%) and US Doctors of Osteopathic Medicine (11\%). Residents completed the online surveys at the beginning of PGY1. In terms of health status, $25 \%(n=50)$ reported a chronic medical condition and 19\% $(n=38)$ reported taking medication for a chronic medical condition. The most common medical conditions reported were psychological (depression, anxiety, and/or attention deficit hyperactivity disorder; $n=15)$, asthma $(n=12)$ and allergies $(n=9)$. More than two-thirds $(68.2 \%$; $n=135 / 198)$ had a normal BMI, while $23 \%(n=46)$ fell in the overweight range and $5 \%$ were in the obese range $(n=10)$. Residents reported experiencing pain an average of 1.3 days in the past seven days (range $0-7)$. Almost half of the residents $(47 \% ; n=95)$ reported experiencing at least one day of pain. Few residents reported taking prescription medication for stress or anxiety $(n=16 ; 8 \%)$. Alcohol consumption averaged 2.8 drinks in the past 7 days, with a maximum of 15 drinks in the past week. Three residents reported smoking cigarettes (2\%). In terms of hours worked in the past week, $92 \%$ $(n=186)$ reported working $80 \mathrm{~h}$ or less with $59 \%(n=119)$ working $61-80 \mathrm{~h}$.

\subsection{Wellbeing Measures}

Descriptive statistics for the wellbeing measures are presented in Table 2. The average perceived stress score (16) for this resident sample was slightly higher than normed sample data for the general public (11.9-14.7), but was consistent with ranges for healthcare students (15.5-16.7) [23]. The average depression score (12.9) was within the non-depressed range, with $70 \%$ of the sample scoring in this range. However, $30 \%$ scored over 16, the cut-off score indicating a risk for clinical depression [14,24]. Over half the sample (55\%) scored in the low emotional exhaustion range. Less than half (42\%) scored in the low depersonalization range. Twenty percent of residents scored in the high emotional exhaustion range and 32\% scored in the high depersonalization range. Fifteen percent scored in the high burnout range on both the emotional exhaustion and depersonalization scales. The average score on personal accomplishment (29.5) was in the low range (high risk for burnout) [15]. The average life satisfaction score was 26.4 (in the satisfied range) with $68.9 \%$ scoring in the satisfied to extremely satisfied range $[17,18]$. The mean positive affect (35.2) and negative affect scores (20.6) were slightly better than the mid-point (30) on the Positive and Negative Affect Schedule (PANAS) scale and consistent with what was observed in incoming family medicine residents in the Integrative Medicine in Residency (IMR) program [25].

The average mindfulness score (35.4) was slightly higher than a general sample [20]. Residents in the current sample scored lower on perspective taking and empathic concern and higher on personal distress than a study of incoming internal medicine residents [26]. The average empathy score in this resident sample (110.75) is lower than means obtained in the Jefferson Empathy Scale (JES) validation study with both resident and medical student samples (118) [22]. 
Table 2. Measures of wellbeing-descriptive statistics.

\begin{tabular}{|c|c|c|c|c|c|}
\hline Wellbeing Measures & $N$ & $n$ & Mean (SD)/\% Yes & Range & Norm Data \\
\hline Perceived stress & 190 & & $16.0(5.9)$ & $2-31$ & $11.9-14.7^{1}$ \\
\hline CES-D depression & 190 & & $12.9(9.2)$ & $0-42$ & \\
\hline Non-depressed & & 132 & $69.5 \%$ & & $<16$ non-depressed \\
\hline Clinical depression risk & & 58 & $30.5 \%$ & & $\geq 16$ \\
\hline MBI-Emotional exhaustion & 203 & & $18.1(9.0)$ & $0-54$ & 19-26 average \\
\hline Low emotional exhaustion & & 112 & $55.2 \%$ & & \\
\hline $\begin{array}{l}\text { Moderate emotional } \\
\text { exhaustion }\end{array}$ & & 50 & $24.6 \%$ & & \\
\hline High emotional exhaustion & & 41 & $20.2 \%$ & & \\
\hline MBI-Depersonalization & 203 & & $7.4(4.9)$ & $0-30$ & 6-9 average \\
\hline Low depersonalization & & 85 & $41.9 \%$ & & \\
\hline Moderate depersonalization & & 54 & $26.6 \%$ & & \\
\hline High depersonalization & & 64 & $31.5 \%$ & & \\
\hline MBI-Burnout risk group & & & & & \\
\hline Low risk & & 70 & $34.5 \%$ & & \\
\hline Moderate risk & & 102 & $50.2 \%$ & & \\
\hline High risk & & 31 & $15.3 \%$ & & \\
\hline $\begin{array}{l}\text { MBI-Personal } \\
\text { accomplishment }\end{array}$ & 203 & & $29.5(6.3)$ & $12-48$ & 39-34 average \\
\hline Satisfaction with life & 203 & & $26.4(5.8)$ & $5-35$ & 26-30 satisfied \\
\hline PANAS Positive & 174 & & $35.2(6.4)$ & $10-50$ & $35.3^{2}$ \\
\hline PANAS Negative & 174 & & $20.6(6.0)$ & $10-42$ & $19.6^{3}$ \\
\hline Mindfulness & 191 & & $35.4(7.1)$ & $16-54$ & $34.52^{3}, 31.17^{4}$ \\
\hline IRI Empathic concern & 190 & & $21.5(4.0)$ & $11-28$ & $22.2^{5}$ \\
\hline IRI Personal distress & 190 & & $10.4(4.9)$ & $0-25$ & $8.9^{5}$ \\
\hline IRI Perspective taking & 189 & & $18.3(4.3)$ & $2-28$ & $20.6^{5}$ \\
\hline Jefferson empathy & 174 & & $110.7(14.2)$ & $79-140$ & $118^{6}$ \\
\hline
\end{tabular}

${ }^{1}$ General public validation sample; ${ }^{2}$ Post Graduate Year (PGY1) Family medicine residents; ${ }^{3}$ General sample;

${ }^{4}$ Clinical sample; ${ }^{5}$ PGY1 Internal medicine residents; ${ }^{6}$ Resident and medical student mean, SD: standard deviation.

\subsection{Lifestyle Behaviors}

Descriptive statistics for the lifestyle behavior items by domain are presented in Table 3. Eating breakfast was the most frequent behavior (mean $=5.7$ days), while eating 5 servings of fruits and vegetables was the least frequent (mean $=3.3$ days). Most did not drink sugary beverages $(60 \%)$. Residents reported an average of 2 days of at least $10 \mathrm{~min}$ moderate exercise and 1.6 days of $10 \mathrm{~min}$ of vigorous exercise. More than half of residents reported either 1-2 days (42\%) or 3-4 days $(28 \%)$ of $30 \mathrm{~min}$ of moderate exercise. Most residents (83\%) reported sedentary behavior less than $70 \%$ on an average day. Residents reported engaging in an activity to manage stress an average of 3.3 days. The most frequent practice was prayer (mean 2.3 days). The least frequent practice was progressive muscle relaxation (mean $=0.2$ days). While residents reported spending time in nurturing relationships with family or friends most days (mean $=4.8$ days), much less time was spent socializing with friends (mean $=2.1$ days). Most residents $(74 \%)$ reported feeling a sense of belonging to a group. While getting $7-9 \mathrm{~h}$ of sleep $($ mean $=3.4$ days) or waking feeling rested (mean $=3$ days) averages were somewhat low, trouble staying asleep was not a frequent issue (mean $=1.4$ days). Residents reported enjoying work an average of 4.6 days and feeling overwhelmed 2.6 days per week. 
Table 3. Lifestyle behaviors-descriptive statistics.

\begin{tabular}{|c|c|c|c|c|c|}
\hline Domain/Items & $N$ & $n$ & Mean/\% & SD & Range \\
\hline \multicolumn{6}{|l|}{ Diet/Nutrition } \\
\hline 5 Servings fruits \& vegetables & 203 & & 3.3 & 2.2 & $0-7$ \\
\hline Eat calcium rich foods & 203 & & 4.9 & 2.0 & $0-7$ \\
\hline Eat breakfast & 200 & & 5.7 & 1.9 & $0-7$ \\
\hline Eat home cooked dinner & 203 & & 4.2 & 2.0 & $0-7$ \\
\hline Drank caffeinated beverages * & 203 & & 5.6 & 2.2 & $0-7$ \\
\hline Sugary fluid drinks average day * & 202 & & 0.6 & 0.9 & $0-5$ \\
\hline 0 & & 122 & $60.4 \%$ & & \\
\hline 1 & & 61 & $30.2 \%$ & & \\
\hline 2 & & 8 & $3.9 \%$ & & \\
\hline 3 & & 9 & $4.5 \%$ & & \\
\hline 4 & & 1 & $0.5 \%$ & & \\
\hline 5 or more & & 1 & $0.5 \%$ & & \\
\hline Servings high fiber average day & 203 & & 2.1 & 1.3 & $0-5$ \\
\hline 0 & & 15 & $7.4 \%$ & & \\
\hline 1 & & 51 & $25.1 \%$ & & \\
\hline 2 & & 67 & $33.0 \%$ & & \\
\hline 3 & & 43 & $21.2 \%$ & & \\
\hline 4 & & 14 & $6.9 \%$ & & \\
\hline 5 or more & & 13 & $6.4 \%$ & & \\
\hline Vegetarian & 188 & & 0.07 & 0.25 & $0-1$ \\
\hline Yes & & 13 & $6.9 \%$ & & \\
\hline \multicolumn{6}{|l|}{ Exercise } \\
\hline Vigorous physical activity $\geq 10 \mathrm{~min}$ & 202 & & 1.6 & 1.8 & $0-7$ \\
\hline Moderate physical activity $\geq 10 \mathrm{~min}$ & 202 & & 2.0 & 2.0 & $0-7$ \\
\hline Moderate physical activity $\geq 30 \mathrm{~min}$ & 187 & & & & \\
\hline None & & 28 & $15.0 \%$ & & \\
\hline $1-2$ days & & 78 & $41.7 \%$ & & \\
\hline 3-4 days & & 53 & $28.3 \%$ & & \\
\hline 5-6 days & & 21 & $11.2 \%$ & & \\
\hline Everyday & & 7 & $3.7 \%$ & & \\
\hline Percent sedentary average day * & 198 & & & & \\
\hline Less than $5 \%$ & & 4 & $2.0 \%$ & & \\
\hline $6-10 \%$ & & 8 & $4.0 \%$ & & \\
\hline $11-20 \%$ & & 12 & $6.1 \%$ & & \\
\hline $21-30 \%$ & & 19 & $9.6 \%$ & & \\
\hline $31-40 \%$ & & 25 & $12.6 \%$ & & \\
\hline $41-50 \%$ & & 36 & $18.2 \%$ & & \\
\hline $51-60 \%$ & & 29 & $14.6 \%$ & & \\
\hline $61-70 \%$ & & 31 & $15.7 \%$ & & \\
\hline $71-80 \%$ & & 25 & $12.6 \%$ & & \\
\hline $81-90 \%$ & & 9 & $4.5 \%$ & & \\
\hline $91-100 \%$ & & 0 & $0 \%$ & & \\
\hline \multicolumn{6}{|l|}{ Mind-Body/Spiritual Practices } \\
\hline Activity to relax or manage stress & 202 & & 3.3 & 2.4 & $0-7$ \\
\hline Prayer & 202 & & 2.3 & 2.8 & $0-7$ \\
\hline Spiritual ritual non-prayer & 202 & & 0.6 & 1.7 & $0-7$ \\
\hline Personal reflection & 201 & & 1.5 & 2.2 & $0-7$ \\
\hline Breathing for stress reduction & 202 & & 0.5 & 1.3 & $0-7$ \\
\hline Progressive muscle relaxation & 191 & & 0.2 & 0.8 & $0-7$ \\
\hline \multicolumn{6}{|l|}{ Social Support Activities } \\
\hline Spend time family/friends & 203 & & 4.8 & 2.3 & $0-7$ \\
\hline Receive healthy touch & 203 & & 4.4 & 2.6 & $0-7$ \\
\hline Socialize with friends & 202 & & 2.1 & 1.6 & $0-7$ \\
\hline Sense of belonging groups & 203 & & & & \\
\hline Yes & & 150 & $73.9 \%$ & & \\
\hline Not sure & & 20 & $9.9 \%$ & & \\
\hline No & & 33 & $16.3 \%$ & & \\
\hline Number groups belong & 203 & & 1.9 & 1.2 & $0-6$ \\
\hline \multicolumn{6}{|l|}{ Sleep } \\
\hline Get 7-9 h of sleep & 203 & & 3.4 & 2.2 & $0-7$ \\
\hline Wake feeling rested & 201 & & 3.0 & 2.1 & $0-7$ \\
\hline Trouble staying asleep * & 201 & & 1.4 & 2.0 & $0-7$ \\
\hline
\end{tabular}


Table 3. Cont.

\begin{tabular}{cccccc}
\hline Domain/Items & $\boldsymbol{N}$ & $\boldsymbol{n}$ & Mean/\% & SD & Range \\
\hline Hobbies & 202 & 2.1 & 2.3 & $0-7$ \\
\hline Number of Alcohol Drinks & 200 & 2.8 & 3.0 & $0-15$ \\
\hline Work & & & & \\
\hline Enjoy work & & & & \\
\hline Feel overwhelmed by work & 203 & & & & \\
\hline
\end{tabular}

* Items reverse-scored when creating scales.

\subsection{Differences between Burnout Risk Groups on Wellbeing and Lifestyle Behaviors}

In the analyses examining the impact of burnout risk level on wellbeing, all of the models were statistically significant $(p<0.006$; Table 4$)$. In comparing the burnout risk groups, the low burnout risk group experienced significantly greater wellbeing than the high-risk group $(p<0.05)$ in all of the models. Specifically, the low burnout risk group experienced less perceived stress, depression, negative affect, and personal distress and greater satisfaction with life, positive affect, mindfulness, empathic concern, perspective taking, and empathy than the high-risk burnout group $(p<0.05)$. Differences between the moderate burnout risk group and the high burnout risk group were also observed for perceived stress, depression, negative affect, satisfaction with life, positive affect, mindfulness, perspective taking and empathy $(p<0.05)$, with the moderate risk group experiencing greater wellbeing than the high-risk group. The low burnout risk group was significantly different from the moderate burnout risk group, experiencing less perceived stress, depression, and negative affect and greater positive affect, empathic concern, and empathy $(p<0.05)$. All post hoc group comparisons were statistically significant in the perceived stress, depression, negative affect, positive affect, and empathy analyses, indicating that wellbeing decreased significantly as burnout risk increased.

Table 4. Results of one-way variance analysis (ANOVA) for Burnout Group and wellbeing-means and standard deviations.

\begin{tabular}{|c|c|c|c|c|c|c|c|c|}
\hline \multirow[t]{2}{*}{ Wellbeing Measures } & \multirow[t]{2}{*}{ Total $N^{*}$} & \multicolumn{2}{|c|}{$\begin{array}{c}\text { Low Risk } \\
n=70\end{array}$} & \multicolumn{2}{|c|}{$\begin{array}{c}\text { Moderate } \\
\text { Risk } n=102\end{array}$} & \multicolumn{2}{|c|}{$\begin{array}{l}\text { High Risk } \\
\quad n=31\end{array}$} & \multirow[t]{2}{*}{$p$-Value } \\
\hline & & Mean & SD & Mean & SD & Mean & SD & \\
\hline Perceived Stress & 190 & $12.6^{\mathrm{a}, \mathrm{c}}$ & 5.1 & $16.4^{\mathrm{b}}$ & 4.9 & 22.7 & 4.4 & $<0.001$ \\
\hline CES-D Total & 190 & $8.1^{\mathrm{a}, \mathrm{c}}$ & 5.7 & $12.6^{\mathrm{b}}$ & 8.0 & 25.2 & 8.3 & $<0.001$ \\
\hline Satisfaction with Life & 203 & $27.9^{\mathrm{a}}$ & 4.3 & $27.0^{\mathrm{b}}$ & 5.3 & 21.1 & 7.4 & $<0.001$ \\
\hline PANAS Positive & 174 & $38.0^{\mathrm{a}, \mathrm{c}}$ & 4.5 & $35.4^{\mathrm{b}}$ & 6.4 & 28.6 & 4.6 & $<0.001$ \\
\hline PANAS Negative & 174 & $17.5^{\mathrm{a}, \mathrm{c}}$ & 4.6 & $20.5^{b}$ & 5.2 & 27.8 & 4.9 & $<0.001$ \\
\hline FMI Mindfulness & 191 & $37.6^{\mathrm{a}}$ & 6.9 & $35.1^{b}$ & 7.1 & 31.6 & 6.4 & 0.001 \\
\hline IRI Empathic Concern & 190 & $22.8^{\mathrm{a}, \mathrm{c}}$ & 3.7 & 21.2 & 3.9 & 19.7 & 3.9 & 0.001 \\
\hline IRI Perspective Taking & 189 & $19.5^{\mathrm{a}}$ & 4.1 & $18.2^{b}$ & 3.8 & 15.5 & 5.2 & $<0.001$ \\
\hline IRI Personal Distress & 190 & $9.3^{\mathrm{a}}$ & 4.7 & 10.4 & 4.8 & 12.7 & 4.7 & 0.006 \\
\hline Jefferson Empathy & 174 & $115.8^{\mathrm{a}, \mathrm{c}}$ & 13.0 & $110.6^{\mathrm{b}}$ & 13.2 & 99.2 & 14.1 & $<0.001$ \\
\hline \multicolumn{9}{|l|}{ Lifestyle Behaviors } \\
\hline Diet/Nutrition & 203 & 0.084 & 0.51 & $0.043^{\mathrm{b}}$ & 0.40 & -0.20 & 0.62 & 0.048 \\
\hline Exercise $^{\mathrm{d}}$ & 203 & 0.045 & 0.7 & 0.053 & 0.7 & -0.25 & 0.6 & 0.095 \\
\hline $\begin{array}{l}\text { Mind-body/Spiritual } \\
\text { Practices }\end{array}$ & 203 & 1.6 & 1.2 & 1.4 & 1.0 & 1.1 & 1.1 & 0.13 \\
\hline Social Support Activities $\mathrm{d}$ & 203 & $0.018^{\mathrm{a}}$ & 0.7 & $0.075^{\mathrm{b}}$ & 0.6 & -0.30 & 0.7 & 0.012 \\
\hline Sleep & 203 & $4.4^{\mathrm{a}}$ & 1.5 & $4.1^{\mathrm{b}}$ & 1.4 & 2.9 & 1.3 & $<0.001$ \\
\hline Hobbies & 202 & 2.3 & 2.6 & 2.0 & 2.1 & 1.8 & 2.1 & 0.56 \\
\hline Alcohol drinks & 200 & 2.5 & 2.7 & 3.2 & 2.9 & 2.5 & 3.6 & 0.32 \\
\hline Work Stress & 203 & $1.7^{\mathrm{a}, \mathrm{c}}$ & 1.1 & $2.6^{\mathrm{b}}$ & 1.5 & 4.2 & 1.6 & $<0.001$ \\
\hline
\end{tabular}

${ }^{*} N$ varied by measure. Post hoc Tukey tests: ${ }^{\text {a }}$ low-risk vs. high-risk group, $p<0.05 ;{ }^{\mathrm{b}}$ moderate-risk vs. high-risk group, $p<0.05{ }^{\mathrm{c}}$ low-risk vs. moderate-risk group, $p<0.05{ }^{\mathrm{d}}$ means for exercise and social relationships are $z$-scores, therefore the group mean is zero. Means greater than 0 indicate higher frequency than the group mean, while negative means indicate a frequency lower than the group mean. 
For the lifestyle behaviors, the diet/nutrition, social relationships, sleep and work stress models were statistically significant $(p<0.05$; Table 4$)$. The post hoc group comparisons between the low-risk and high-risk groups or moderate-risk and high-risk groups, were statistically significant $(p<0.05)$ in these models. The low-risk and moderate-risk groups reported engaging in a greater frequency of social behaviors and quality sleep than the high-risk group. For diet/nutrition, the high-risk group reported a lower frequency of healthy eating behaviors than the moderate risk group. In the work stress model, the post hoc comparisons were significantly different between all burnout groups, indicating an increase in work stress as burnout risk increased $(p<0.05)$. There was no difference between the burnout risk groups for exercise, mind-body/spiritual practices, hobbies or alcohol use.

\subsection{Relationship between Lifestyle Behaviors and Wellbeing Measures}

Gender was significantly correlated with empathic concern and empathy and, therefore, included in those regression models. Marital status was correlated with life satisfaction and included in that regression model. The various combinations of lifestyle behaviors contributed $6 \%$ to $49 \%$ of the variance in the tested models $\left(\boldsymbol{R}^{2}\right)$, depending on the wellbeing measure examined (see Tables 5 and 6 ). Work stress was a statistically significant predictor in all but one regression model, empathic concern. Greater work stress was associated with increased perceived stress, depression, emotional exhaustion, depersonalization, negative affect, personal distress, and lower personal accomplishment, life satisfaction, positive affect, mindfulness, perspective taking, and empathy. The second-strongest predictor across the wellbeing models was exercise. A higher frequency of engaging in exercise was associated with less perceived stress, depression, negative affect, and personal distress, and higher levels of personal accomplishment, positive affect, mindfulness, perspective taking, and empathy. A higher frequency of engaging in social support activities was associated with higher life satisfaction, mindfulness, and empathic concern and less depression. More quality sleep was associated with less perceived stress, depression, emotional exhaustion, and negative affect. A greater frequency of healthy eating behaviors was associated with lower levels of depersonalization and higher life satisfaction. While a higher frequency of engaging in hobbies was associated with decreased personal distress, it was also associated with less mindfulness. Mind-body/spiritual practices were associated with increased mindfulness only. Alcohol use was non-significant in all the models. Gender was associated with empathic concern and empathy, with females having greater empathic concern and empathy, while marital status was non-significant.

Table 5. Lifestyle behavior predictors, $R^{2}$ and betas on measures of wellbeing ${ }^{\text {a }}$.

\begin{tabular}{|c|c|c|c|c|c|}
\hline Wellbeing Measure & Model Adjusted $R^{2}$ & Model $p$-Value & $\beta$ & $t$ & $p$-Value \\
\hline Perceived stress & 0.39 & $<0.001$ & & & \\
\hline Work stress & & & 0.50 & 7.95 & $<0.001$ \\
\hline Exercise & & & -0.19 & -3.35 & 0.001 \\
\hline Sleep & & & -0.16 & -2.45 & 0.015 \\
\hline CES-D Total & 0.49 & $<0.001$ & & & \\
\hline Work & & & 0.47 & 7.80 & $<0.001$ \\
\hline Sleep & & & -0.23 & -3.93 & $<0.001$ \\
\hline Social & & & -0.18 & -3.14 & 0.002 \\
\hline Exercise & & & -0.13 & -2.38 & 0.018 \\
\hline MBI emotional exhaustion & 0.40 & $<0.001$ & & & \\
\hline Work stress & & & 0.56 & 9.52 & $<0.001$ \\
\hline Sleep & & & -0.17 & -2.94 & 0.004 \\
\hline MBI Depersonalization & 0.16 & $<0.001$ & & & \\
\hline Work stress & & & 0.34 & 5.21 & $<0.001$ \\
\hline Diet & & & -0.20 & -3.09 & 0.002 \\
\hline MBI personal accomplishment & 0.18 & $<0.001$ & & & \\
\hline Work Stress & & & -0.34 & -5.32 & $<0.001$ \\
\hline Exercise & & & 0.23 & 3.64 & $<0.001$ \\
\hline Satisfaction with life $\mathrm{b}^{\mathrm{b}}$ & 0.26 & $<0.001$ & & & \\
\hline Work stress & & & -0.36 & -5.65 & $<0.001$ \\
\hline Social & & & 0.21 & 3.29 & 0.001 \\
\hline Diet & & & 0.16 & 2.60 & 0.010 \\
\hline
\end{tabular}


Table 5. Cont.

\begin{tabular}{|c|c|c|c|c|c|}
\hline Wellbeing Measure & Model Adjusted $R^{2}$ & Model $p$-Value & $\beta$ & $t$ & $p$-Value \\
\hline PANAS positive & 0.31 & $<0.001$ & & & \\
\hline Work stress & & & -0.46 & -7.29 & $<0.001$ \\
\hline Exercise & & & 0.27 & 4.25 & $<0.001$ \\
\hline PANAS negative & 0.26 & $<0.001$ & & & \\
\hline Work stress & & & 0.37 & 5.05 & $<0.001$ \\
\hline Exercise & & & -0.17 & -2.64 & 0.009 \\
\hline Sleep & & & -0.17 & -2.34 & 0.021 \\
\hline Mindfulness & 0.20 & $<0.001$ & & & \\
\hline Work stress & & & -0.27 & -3.95 & $<0.001$ \\
\hline Exercise & & & 0.25 & 3.66 & $<0.001$ \\
\hline Social & & & 0.15 & 2.18 & 0.031 \\
\hline Hobbies & & & -0.16 & -2.27 & 0.024 \\
\hline Mind-body & & & 0.14 & 2.01 & 0.046 \\
\hline IRI empathic concern ${ }^{c}$ & 0.06 & 0.001 & & & \\
\hline Gender & & & 0.20 & 2.77 & 0.006 \\
\hline Social & & & 0.17 & 2.41 & 0.017 \\
\hline IRI perspective taking & 0.064 & 0.001 & & & \\
\hline Work stress & & & -0.20 & -2.76 & 0.006 \\
\hline Exercise & & & 0.18 & 2.47 & 0.014 \\
\hline IRI Personal distress & 0.078 & $<0.001$ & & & \\
\hline Exercise & & & -0.21 & -2.94 & 0.004 \\
\hline Work stress & & & 0.20 & 2.78 & 0.006 \\
\hline Hobbies & & & -0.15 & -1.97 & 0.050 \\
\hline Jefferson empathy ${ }^{c}$ & 0.17 & $<0.001$ & & & \\
\hline Gender & & & 0.29 & 4.11 & $<0.001$ \\
\hline Exercise & & & 0.26 & 3.72 & $<0.001$ \\
\hline Work stress & & & -0.17 & -2.47 & 0.009 \\
\hline
\end{tabular}

${ }^{a}$ Only statistically significant $(p<0.05)$ predictors in final model are presented. b Due to the correlation with marital status, marital status was included in the initial model. However, it was non-significant and was dropped from the final model. Married/cohabitating is coded as 1 , single as $0 .{ }^{c}$ Due to the correlation with gender, gender was included in the model. Gender is coded 1 for male, 2 for female.

Table 6. Lifestyle behavior predictors and relationship to wellbeing measures.

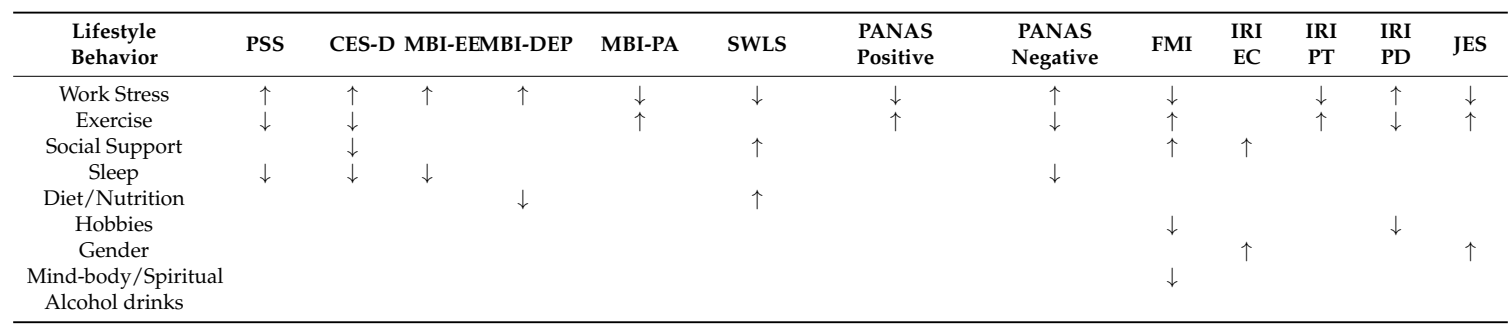

$\uparrow$ Positive relationship between wellness behavior and wellbeing measure; $\downarrow$ Negative relationship between wellness behavior and wellbeing measure.

\subsection{On-Site Physician Wellness Activities}

Wellness retreats were the most frequent type of wellness activity offered, with all sites hosting wellness-focused retreats over the three-year period (see Figure 1). These retreats varied in content-based on-site faculty preferences and available resources. Most were held off-site in a private setting and provided opportunity for small group discussions and peer support, informational seminars, and experiential learning. The next-most frequently reported activity was increased nutrition options for residents, available initially at four sites, and at all sites by 2016. Physical activity options (mainly access to gyms) increased from two sites in 2014 to four sites by 2016. Burnout prevention activities increased from one site in 2014 to four sites; and by 2016, other wellness activities (empathy skills training, self-regulation skills, conflict resolution/communication, and stress management) were offered at three of the five sites. 


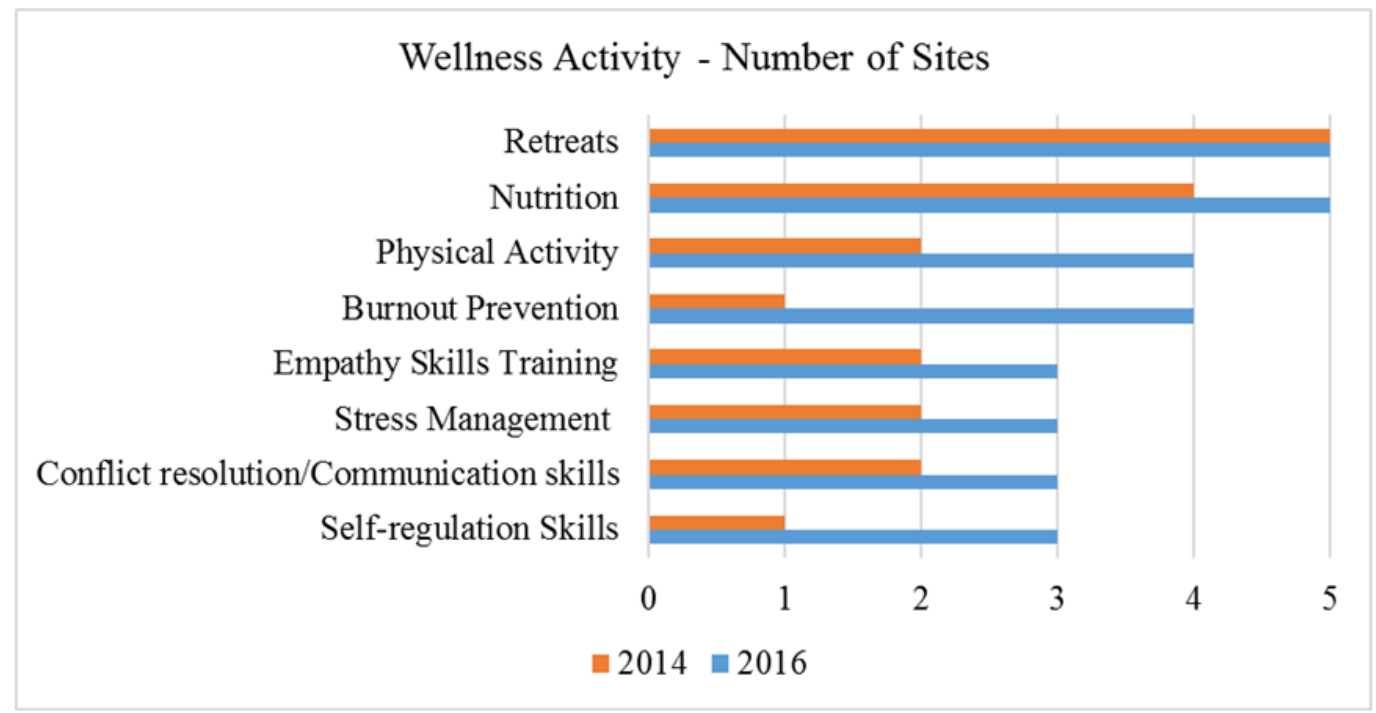

Figure 1. On-site physician wellness activities—number of sites by year.

\section{Discussion}

It is well established that burnout is prevalent in medical trainees and takes a steep toll on mental and physical health [2]. This highlights the need for reform of the current medical education model, and the paradox of recruiting medical students for both their academic strength and empathic qualities. A combination that may predispose talented trainees to distress during the rigors of conventional medical training. Addressing and preventing burnout from the very earliest stages of medical school training is necessary, because burnout impacts patient care, quality of patient counseling, and prevalence of medical errors [7]. The etiology of burnout is complex, involving a variety of factors at the organizational, institutional, and individual levels, requiring coordinated, systems-level solutions [8]. Surveys show that burnout rates in pediatric trainees mirror national prevalence, emphasizing the urgent need for change at the earliest stages of pediatric training in addition to preventive steps and education during medical school to avoid the recurring pitfall of receiving first-year residents already in serious stages of burnout $[4,6]$.

To highlight this point, our study findings demonstrate that a substantial proportion of first-year pediatric residents in the PIMR pilot study began residency with higher levels of burnout and depression and poorer emotional intelligence and empathy than comparison samples, mirroring national trends [6]. Fifteen percent of residents in the study were high risk (high on both emotional exhaustion and depersonalization), 50\% were in the moderate risk (high or moderate in either emotional exhaustion or depersonalization), and 35\% were at low risk. In addition, with respect to depression, $30 \%$ scored in the clinical depression risk range. This is considerably higher than a study of residents and medical students that found $11 \%$ of first year residents were in the clinical depression risk range [27].

In the cohort, as burnout risk increases, overall wellbeing, empathy and emotional intelligence decreases. Residents with high burnout risk also reported more days of experiencing work stress, and had lower wellbeing, social support, stress management behaviors, emotional intelligence, and empathy than residents in the low and moderate risk groups. Overall, work stress was the strongest predictor of burnout, wellbeing, and emotional intelligence in our sample, significant in all models except empathic concern. The sense of feeling overwhelmed and lack of work enjoyment appears to permeate all areas of the resident's life, increasing burnout and decreasing wellbeing, emotional intelligence, mindfulness, and empathy.

Residents in the high-risk burnout group reported lower frequencies of healthy eating, social support activities, and quality sleep than their peers. One in four residents were living with a chronic 
illness, and $28 \%$ of residents entering the PIMR program were either overweight $(23 \%)$ or obese $(5 \%)$, highlighting the links between chronic stress and upregulation of inflammatory cytokines, depression, and other related comorbidities [28-30].

Exercise was a strong predictor of wellbeing and emotional intelligence, associated with less stress and depression, greater personal accomplishment, affect, mindfulness, emotional intelligence and empathy, although not distinguishing between burnout groups. Inadequate sleep was associated with emotional exhaustion, as well as stress, depression, and negative affect, similar to the burnout risk models. Social support activities were associated with less depression and greater life satisfaction, mindfulness, and empathic concern, although contrary to the burnout models, they were not associated with the burnout measures. Higher quality diet/nutrition behaviors were associated with less depersonalization and greater life satisfaction. Female gender was associated with greater empathic concern and empathy.

In our study, mind-body spiritual practices were not associated with any of the burnout, wellbeing, or emotional intelligence measures. One reason for these findings may be due to the low frequency of engagement in these behaviors in this sample. The narrow range may have limited the ability to detect an association to the burnout, wellbeing, and emotional intelligence variables. Fortunately, some residency programs are beginning to teach these behaviors, and future studies will be able to examine the role of mind-body practices in prevention of burnout.

In summary, a majority of residents in the study were at either moderate or high risk of burnout, not meeting basic recommendations for healthy lifestyle habits, and stood a 1 in 4 chance of being overweight or obese. Our findings are consistent with other surveys that document high levels of burnout in graduating US medical students [31], and mirror studies demonstrating lack of regular physical activity in residents [32,33], and published reports of lower levels of stress and burnout in medical students who exercised regularly [34-36]. While the percentage of overweight residents was lower in our sample (23\%) when compared to a study of first year residents from multiple specialties $(34 \%)$ [37], the rate of obese residents in our sample of pediatric residents was higher ( $5 \%$ vs. $0 \%$ ). In addition to the protective lifestyle behaviors mentioned, the remaining wellness activities (empathy skills training, self-regulation skills, conflict resolution/communication, stress management) were offered at 3 of the 5 sites. Ideally, these would serve to help moderate perceived work stress and help build connections at work, cultivating social resilience, which has been shown to be protective against burnout in medical training [38].

National surveys have shown that organizational and institutional measures to reduce and prevent burnout are effective [39,40], and a prudent financial investment [41]. Despite these findings, and widespread recognition of burnout's mental and physical toll, few programs offer approaches to promote self-care activities associated with lower burnout prevalence [34,42-44].

The PIMR program addresses these gaps in two important ways. First, by embedding a curriculum on protective lifestyle behaviors into residency training, the concept of self-care is acknowledged and normalized. Second, engagement of a critical mass of residents and faculty instructors participating in and teaching these activities drives broader culture change within individual organizations. In our study, this is borne out by the increase in program wellness activities over time. Perhaps most notable is the increase from only 1 site offering burnout prevention activities in 2014 to 4 sites with burnout prevention activities in 2016. Newly revised ACGME competencies mandating specific attention to resident wellbeing will hopefully provide critical leverage to move this initiative forward [9].

Furthermore, promotion of healthy lifestyle behaviors in residents aligns with developing themes in the medical literature suggesting that trainees with healthier lifestyle habits are more likely to counsel patients on healthy lifestyle habits, and to do so more effectively than their less healthy colleagues [45-47]. This point has special relevance in pediatric trainees, who have the potential to encourage a lifetime of healthy habits in their young patients. 


\section{Limitations}

One of the main limitations of this study is the limited generalizability of the findings. The five participating residencies were not randomly selected but volunteered to participate to pilot a new integrative medicine curriculum. Given that there are nearly 200 pediatric residencies nationwide, it is not possible to determine the representativeness of these 5 sites. In addition, the response rate was $63 \%$ across the sites, with variation in the response rate between the sites, also limiting our ability to generalize our findings. Data was collected during the first trimester of residency and does not reflect the full measure of residency stressors that accumulate throughout residency.

A second limitation is our primary emphasis on lifestyle behaviors as potential mediators/moderators in the relationship between stress and burnout and its consequent effects. Individual factors that can mediate the impact of stress, such as cognitive appraisals, coping styles and strategies, self-efficacy expectations, grit, optimism, resiliency, hardiness, and social competence were not assessed. System level factors were also not assessed. These include current rotations, prior experience, and levels of faculty support and burnout and how this influences resident burnout, all areas of active study. The newly developed lifestyle behavior instrument used in this study may not have fully captured the lifestyle behaviors most critical to wellbeing. Further, the lifestyle behaviors were captured retrospectively, thus it was not possible to confirm the accuracy of the self-reported lifestyle behaviors with other methods, such as daily recording of the behavior. Lastly, the study utilized online self-report surveys which may be subject to recall bias and social desirability influences.

Future directions could address efforts to increase the reach of the PIMR program by increasing the number of enrolled sites and residents, thereby increasing reach and diversity. Another strategy might include a more tailored rollout of self-care curriculum modules designed to educate leaders and encourage a culture of wellness and engagement within the top levels of organizations [48].

\section{Conclusions}

Accruing research suggests that first-year residents enter training with high levels of burnout, emphasizing the need for effective solutions to address burnout in medical education. Burnout prevalence in our study supported these findings. Furthermore, high burnout risk was associated with a decrease in overall wellbeing, increased work stress, inadequate sleep, fewer social support activities, and poorer diet quality. New mandates from the ACGME to promote resident wellbeing are encouraging, yet few educational programs currently exist to meet these requirements. National surveys show that organizational measures designed to reduce burnout have proven effective. The PIMR program offers an innovative curriculum that residency programs can use to target protective lifestyle behaviors correlated with decreased burnout measures. These include physical activity, sleep, nutrition, and stress management/coping skills. Within the PIMR program, education about these behaviors is delivered in a train the trainer educational model that will ideally equip residents to become more effective role models and counselors to their young patients.

Author Contributions: H.M. and A.J.B. conceived and designed the study; H.M., A.J.B., M.-K.C., M.B., M.B., A.E., D.G., B.G., J.M., J.W., and A.M.Y. participated in study design and data collection; H.M., A.J.B. and M.-K.C. analyzed and interpreted the data; H.M. and A.J.B. wrote the body of the paper, and all authors contributed substantially to individual sections and editing of drafts.

Acknowledgments: Sincere thanks to all the residents and faculty participating in the PIMR pilot program, as well as to all faculty involved in the early adopter phase including: Maria Mascarenhas and Miriam Stewart, Children's Hospital of Philadelphia; Carmen Herrera, University of New Mexico; Alexandra Russell, Vanderbilt University; Rukmani Vasan, University of Southern California; Marian Eckert, Kinderkrankenhaus St. Marien; Elena Ladas, Columbia University; Hillary Franke, University of Arizona; J. Paige Frazer, Eastern Virginia Medical School, Children's Hospital of the King's Daughters. Thanks also go to Paula Cook, Research Specialist, and Rhonda Hallquist, Instructional Web Developer, for their many contributions. And a special thanks to Emily Sherbrooke, IMR/PIMR Program Coordinator Sr.; and to Janice Curtis, Administrative Associate, for their administrative support and expert help in manuscript preparation. Funding was received from the David and Lura Lovell Foundation, the Weil Foundation, the Gerald J. and Rosalie E. Kahn Family Foundation, Inc., the John F. Long Foundation, the Resnick Foundation, and the Sampson Foundation. 
Conflicts of Interest: The authors declare no conflict of interest.

\section{References}

1. Dyrbye, L.N.; West, C.P.; Satele, D.; Boone, S.; Tan, L.; Sloan, J.; Shanafelt, T.D. Burnout among US medical students, residents, and early career physicians relative to the general US population. Acad. Med. 2014, 89, 443-451. [CrossRef] [PubMed]

2. Dyrbye, L.; Shanafelt, T. A narrative review on burnout experienced by medical students and residents. Med. Educ. 2016, 50, 132-149. [CrossRef] [PubMed]

3. McClafferty, H.; Brown, O.W. Physician health and wellness. Pediatrics 2014, 134, 830-835. [CrossRef] [PubMed]

4. Pantaleoni, J.L.; Augustine, E.M.; Sourkes, B.M.; Bachrach, L.K. Burnout in pediatric residents over a 2-year period: A longitudinal study. Acad. Pediatr. 2014, 14, 167-172. [CrossRef] [PubMed]

5. Mahan, J.D. Burnout in pediatric residents and physicians: A call to action. Pediatrics 2017, 139, e20164233. [CrossRef] [PubMed]

6. Baer, T.E.; Feraco, A.M.; Sagalowsky, S.T.; Williams, D.; Litman, H.J.; Vinci, R.J. Pediatric resident burnout and attitudes toward patients. Pediatrics 2017, 139, e20162163. [CrossRef] [PubMed]

7. Jennings, M.L.; Slavin, S.J. Resident wellness matters: Optimizing resident education and wellness through the learning environment. Acad. Med. 2015, 90, 1246-1250. [CrossRef] [PubMed]

8. Shanafelt, T.D.; Dyrbye, L.N.; West, C.P. Addressing physician burnout: The way forward. JAMA 2017, 317, 901-902. [CrossRef] [PubMed]

9. Accreditation Council for Graduate Medical Education (ACGME). Revised Common Program Requirements, Section VI, The Learning and Working Environment. Available online: https: / www.acgmecommon.org/ press_release (accessed on 2 March 2017).

10. Accreditation Council for Graduate Medical Education (ACGME). Physician Wellbeing. Available online: http:/ / www.acgme.org/What-We-Do/Initiatives / Physician-Well-Being (accessed on 3 February 2017).

11. McClafferty, H.; Dodds, S.; Brooks, A.J.; Brenner, M.; Brown, M.; Frazer, P.; Mark, J.; Weydert, J.; Wilcox, G.; Lebensohn, P.; Maizes, V. Pediatric integrative medicine in residency (PIMR): Description of a new online educational curriculum. Children 2015, 2, 98-107. [CrossRef] [PubMed]

12. Lebensohn, P.; Brooks, A.J.; Chen, M.K. A multi-dimensional integrative health measure to assess wellness behaviors-The Arizona lifestyle inventory. In Proceedings of the International Conference to Promote Resilience, Empathy and Well-Being in Health Care Professions (CENTILE 2017), Washington, DC, USA, 22-25 October 2017.

13. Cohen, S.; Kamarck, T.; Mermelstein, R. A global measure of perceived stress. J. Health Soc. Behav. 1983, 24, 385-396. [CrossRef] [PubMed]

14. Radloff, L.S. The CES-D scale: A self-report depression scale for research in the general population. Appl. Psychol. Meas. 1977, 1, 385-401. [CrossRef]

15. Maslach, C.; Jackson, S.E.; Leiter, M.P. Maslach Burnout Inventory, 3rd ed.; Consulting Psychologists Press: Palo Alto, CA, USA, 1996.

16. Maslach, C.; Jackson, S.E.; Leiter, M. Maslach Burnout Inventory Manual, 4th ed.; Mind Garden Inc.: Menlo Park, CA, USA, 2016.

17. Diener, E.; Emmons, R.A.; Larsen, R.J.; Griffin, S. The satisfaction with life scale. J. Pers. Assess. 1985, 49, 71-75. [CrossRef] [PubMed]

18. Pavot, W.; Diener, E. Review of the satisfaction with life scale. Psychol. Assess. 1993, 5, 164-172. [CrossRef]

19. Watson, D.; Clark, L.A.; Tellegen, A. Development and validation of brief measures of positive and negative affect: The PANAS scales. J. Pers. Soc. Psychol. 1988, 54, 1063-1070. [CrossRef] [PubMed]

20. Walach, H.; Buchheld, N.; Buttenmüller, V.; Kleinknecht, N.; Schmidt, S. Measuring mindfulness-The Freiburg mindfulness inventory (FMI). Pers. Individ. Dif. 2006, 40, 1543-1555. [CrossRef]

21. Davis, M.H. Measuring individual differences in empathy: Evidence for a multidimensional approach. J. Pers. Soc. Psychol. 1983, 44, 113-126. [CrossRef]

22. Hojat, M.; Mangione, S.; Nasca, T.J.; Cohen, M.J.M.; Gonnella, J.S.; Erdmann, J.B.; Veloski, J.; Magee, M. The Jefferson scale of physician empathy: Development and preliminary psychometric data. Educ. Psychol. Meas. 2001, 61, 349-365. [CrossRef] 
23. Birks, Y.; McKendree, J.; Watt, I. Emotional intelligence and perceived stress in healthcare students: A multi-institutional, multi-professional survey. BMC Med. Educ. 2009, 9, 61. [CrossRef] [PubMed]

24. Weissman, M.M.; Sholomskas, D.; Pottenger, M.; Prusoff, B.A.; Locke, B.Z. Assessing depressive symptoms in five psychiatric populations: A validation study. Am. J. Epidemiol. 1977, 106, 203-214. [CrossRef] [PubMed]

25. Lebensohn, P.; Dodds, S.; Brooks, A.J.; Cook, P.; Schneider, C.D.; Woytowicz, J.; Maizes, V. A longitudinal study of well-being, burnout and emotional intelligence in family medicine residents. In Proceedings of the International Research Congress on Integrative Medicine and Health, Miami, FL, USA, 13-16 May 2014.

26. Bellini, L.M.; Shea, J.A. Mood change and empathy decline persist during three years of internal medicine training. Acad. Med. 2005, 80, 164-167. [CrossRef] [PubMed]

27. Goebert, D.; Thompson, D.; Takeshita, J.; Beach, C.; Bryson, P.; Ephgrave, K.; Kent, A.; Kunkel, M.; Schechter, J.; Tate, J. Depressive symptoms in medical students and residents: A multischool study. Acad. Med. 2009, 84, 236-241. [CrossRef] [PubMed]

28. Park, Y.-M.; Zhang, J.; Steck, S.E.; Cohen, M.J.M.; Gonnella, J.S.; Erdmann, J.B.; Veloski, J.; Magee, M. Obesity mediates the association between Mediterranean diet consumption and insulin resistance and inflammation in US Adults. J. Nutr. 2017, 147, 563-571. [CrossRef] [PubMed]

29. Chao, A.M.; Jastreboff, A.M.; White, M.A.; Grilo, C.M.; Sinha, R. Stress, cortisol, and other appetite-related hormones: Prospective prediction of 6-month changes in food cravings and weight. Obesity 2017, 25, 713-720. [CrossRef] [PubMed]

30. Razzoli, M.; Pearson, C.; Crow, S.; Bartolomucci, A. Stress, overeating, and obesity: Insights from human studies and preclinical models. Neurosci. Biobehav. Rev. 2017, 76, 154-162. [CrossRef] [PubMed]

31. Dyrbye, L.N.; Moutier, C.; Durning, S.J.; Massie, F.S., Jr.; Power, D.V.; Eacker, A.; Harper, W.; Thomas, M.R.; Satele, D.; Sloan, J.A.; Shanafelt, T.D. The problems program directors inherit: Medical student distress at the time of graduation. Med. Teach. 2011, 33, 756-758. [CrossRef] [PubMed]

32. Daneshvar, F.; Weinreich, M.; Daneshvar, D.; Sperling, M.; Salmane, C.; Yacoub, H.; Gabriels, J.; McGinn, T.; Smith, M.C. Cardiorespiratory fitness in internal medicine residents: Are future physicians becoming deconditioned? J. Grad. Med. Educ. 2017, 9, 97-101. [CrossRef] [PubMed]

33. Williams, A.S.; Williams, C.D.; Cronk, N.J.; Kruse, R.L.; Ringdahl, E.N.; Koopman, R.J. Understanding the exercise habits of residents and attending physicians: A mixed methodology study. Fam. Med. 2015, 47, 118-123. [PubMed]

34. Dyrbye, L.N.; Satele, D.; Shanafelt, T.D. Healthy exercise habits are associated with lower risk of burnout and higher quality of life among US medical students. Acad. Med. 2017, 92, 1006-1011. [CrossRef] [PubMed]

35. Olson, S.M.; Odo, N.U.; Duran, A.M.; Pereira, A.G.; Mandel, J.H. Burnout and physical activity in Minnesota internal medicine resident physicians. J. Grad. Med. Educ. 2014, 6, 669-674. [CrossRef] [PubMed]

36. Frank, E.; Tong, E.; Lobelo, F.; Carrera, J.; Duperly, J. Physical activity levels and counseling practices of US medical students. Med. Sci. Sports Exerc. 2008, 40, 413-421. [CrossRef] [PubMed]

37. Leventer-Roberts, M.; Zonfrillo, M.R.; Yu, S.; Dziura, J.D.; Spiro, D.M. Overweight physicians during residency: A cross-sectional and longitudinal study. J. Grad. Med. Educ. 2013, 5, 405-411. [CrossRef] [PubMed]

38. McKenna, K.M.; Hashimoto, D.A.; Maguire, M.S.; Bynum, W.E. The missing link: Connection is the key to resilience in medical education. Acad. Med. 2016, 91, 1197-1199. [CrossRef] [PubMed]

39. West, C.P.; Dyrbye, L.N.; Erwin, P.J.; Shanafelt, T.D. Interventions to prevent and reduce physician burnout: A systematic review and meta-analysis. Lancet 2016, 388, 2272-2281. [CrossRef]

40. Panagioti, M.; Panagopoulou, E.; Bower, P. Controlled interventions to reduce burnout in physicians: A systematic review and meta-analysis. JAMA Intern. Med. 2017, 177, 195-205. [CrossRef] [PubMed]

41. Shanafelt, T.; Goh, J.; Sinsky, C. The business case for investing in physician well-being. JAMA Intern. Med. 2017, 177, 1826-1832. [CrossRef] [PubMed]

42. Heinen, I.; Bullinger, M.; Kocalevent, R.D. Perceived stress in first year medical students-Associations with personal resources and emotional distress. BMC Med. Educ. 2017, 17, 4. [CrossRef] [PubMed]

43. Thompson, G.; McBride, R.B.; Hosford, C.C.; Halaas, G. Resilience among medical students: The role of coping style and social support. Teach. Learn. Med. 2016, 28, 174-182. [CrossRef] [PubMed]

44. Ward, S.; Outram, S. Medicine: In need of culture change. Intern. Med. J. 2016, 46, 112-116. [CrossRef] [PubMed]

45. Howe, A.; Smajdor, A.; Stockl, A. Towards an understanding of resilience and its relevance to medical training. Med. Educ. 2012, 46, 349-356. [CrossRef] [PubMed] 
46. Frank, E.; Rothenberg, R.; Lewis, C.; Belodoff, B.F. Correlates of physicians' prevention-related practices. Findings from the Women Physicians' Health Study. Arch. Fam. Med. 2000, 9, 359-367. [CrossRef] [PubMed]

47. Frank, E.; Breyan, J.; Elon, L. Physician disclosure of healthy personal behaviors improves credibility and ability to motivate. Arch. Fam. Med. 2000, 9, 287-290. [CrossRef] [PubMed]

48. McClafferty, H.; Ricker, M.; Brooks, A.J.; Lebensohn, P. Cracking the nut: Wellbeing in training, increasing resilience in both individuals \& across healthcare organizations. In Proceedings of the International Conference to Promote Resilience, Empathy and Well-Being in Health Care Professions (CENTILE 2017), Washington, DC, USA, 22-25 October 2017.

(C) 2018 by the authors. Licensee MDPI, Basel, Switzerland. This article is an open access article distributed under the terms and conditions of the Creative Commons Attribution (CC BY) license (http://creativecommons.org/licenses/by/4.0/). 